\title{
CORRIGENDUM
}

\section{Association between glutamic acid decarboxylase genes and anxiety disorders, major depression, and neuroticism}

JM Hettema, SS An, MC Neale, J Bukszar, EJCG van den Oord, KS Kendler and X Chen

Molecular Psychiatry (2006) 11, 794. doi:10.1038/sj.mp.4001858

Correction to: Molecular Psychiatry (2006) 11, 752-762.

Line 4. '(i.e., path loadings $>0.05=0.23$ )' should be doi:10.1038/sj.mp.4001845.

'(i.e., path loadings $>\sqrt{ } 0.05=0.23)$.'

Following the online publication of the above article,

the authors noted an error in the legend of Figure 1: 